\title{
An Investigation on the Pharmacological Profile of Titanium (IV) and Aluminum (III) 8-Hydroxyquinoline Derivatives Grafted on MCM-41 Mesoporous Silica
}

\author{
Yousef Fazaeli*, Gholamreza Shahhoseini, Samira Shahbazi, Shahzad Feizi \\ Nuclear Science and Technology Research Institute (NSTRI), Karaj, Iran
}

*Correspondence to

Yousef Fazaeli, Nuclear Science

and Technology Research Institute

(NSTRI), Karaj, Iran. P.O.

Box 31485-498

Tel: 026342057414

Email: youseffazaeli@gmail.com

Received April 25, 2018

Accepted June 2, 2018

Published online September 30, 2018

\begin{abstract}
Introduction: Regarding the increasing applications of nanomedicine in clinical practice, we aimed to assess the antibacterial and anti-fungal effects of nanocomposite complexes of titanium (IV) and aluminum (III).

Methods: 8-hydroxyquinoline and 5-chloro-8-hydroxyquinoline were treated with titanium (IV) and Aluminum (III) alkoxide reagents to generate $(\mathrm{Q})_{2}(2-\mathrm{BuO}) \mathrm{Al}(\mathrm{Q}=8$-hydroxyquinoline and 5-chloro-8-hydroxyquinoline) and $(\mathrm{Q})_{2}(\mathrm{O}-\mathrm{Pr})_{2} \mathrm{Ti}(\mathrm{Q}=5$-chloro-8-hydroxyquinoline) complexes. These active complexes were grafted on MCM-41 mesoporous silica in order to improve the overall toxicity and stability of them. Anti-bacterial and anti-fungal activities of the compounds were assessed.

Results: The prepared materials were stable both under air and high temperature (at least up to $200^{\circ} \mathrm{C}$ ). These nanocomposites were well dispersed in water. It was observed that (Q-Cl)2Ti@MCM-41 nanocomposite had anti-bacterial activity against Staphylococcus aureus at concentrations of 50, 75 and $120 \mathrm{ppm}$ while at the 75 , and $120 \mathrm{ppm}$ concentrations against Escherichia coli and Salmonella typhi. The Q2Al@MCM-41 weakly inhibited the bacterial growth of $E$. coli at 75 and 120 ppm concentrations. (Q-Cl)2Al@MCM-41 did not show any antibacterial activity at any concentration. Moreover, (Q-Cl)2Ti@MCM-41 and (Q-Cl)2Al@MCM41 showed considerable anti-fungal activity against Saccharomyces cerevisiae at 50, 75, 120, and $150 \mathrm{ppm}$ concentrations. The nanoparticles partly inhibited the growth of Kluyveromyces marxianus and Macrophomina phaseolina fungi at 150 ppm concentration.

Conclusion: The results showed that the anti-microbial (bacterium and fungi) effect of the titanium and aluminum nanocomposite complexes can be improved in the solid state using appropriate chlorine substituent on the 8-hydroxyquinoline ligand and grafting to the mesoporous silica. Keywords: MCM-41, Titanium, Aluminum, 8-hydroxyquinoline, Anti-bacterial activity, antifungal activity.
\end{abstract}

\begin{abstract}
Please cite this article as follows: Fazaeli Y, Shahhoseini G, Shahbazi S, Feizi S. An investigation on the pharmacological profile of titanium (IV) and aluminum (III) 8-hydroxyquinoline derivatives grafted on MCM-41 mesoporous silica. Int J Basic Sci Med. 2018;3(3):120126. doi: $10.15171 /$ ijbms.2018.22.
\end{abstract}

\section{Introduction}

Interest in the synthesis of purposeful metalbased composites continues to thrive due to the high demand in medicine. Among non-platinum complexes, aluminum (III) and titanium (IV) have widely been studied due to their unique biological properties such as antitumor, ${ }^{1,2}$ antifungal ${ }^{3}$ and antibacterial ${ }^{4}$ properties. 8-hydroxy quinoline (8-HQ) is a bidentate ligand which can easily form various biologically active complexes with metals. ${ }^{5-16}$ The titanium complexes bearing a quinoline moiety are well known. In particular, 8-hydroxyquinoline and its derivatives were introduced into titanium alkoxides
\end{abstract}

to form mono and centrosymmetric binuclear and tetranuclear complexes. ${ }^{5,17-19}$ Furthermore, changing their physical and biological properties by replacing substituents with 8-hydroxyquinoline and changing endogenous metal is relatively easy. ${ }^{9,20-25}$ The substitution of a chlorine group on the phenolate ring of 8-hydroxyquinoline ligand results in forming biological active complexes among other substituents with subsequently reduced viability in HeLa and PC3 human tumor cells in a dose-dependent manner. Interestingly, adjoining of electron rich compounds (i.e. nitro groups and sulfonic acids) on the hydroxyquinoline ligands

(C) 2018 The Author(s); Published by Zabol University of Medical Sciences. This is an open-access article distributed under the terms of the Creative Commons Attribution License (http://creativecommons.org/licenses/by/4.0), which permits unrestricted use, distribution, and reproduction in any medium, provided the original work is properly cited. 
reduced the antineoplastic potency of complexes up to 220 -fold..$^{9,10}$ In spite of many therapeutic advantages of these complexes, they have some limitations including rapid hydrolysis in moist conditions, lack of stability and forming multinuclear complexes reducing their biological activity. ${ }^{26}$

In this regard, several efforts have been dedicated to improving the stability of these complexes, such as introducing nitrogen- and sulfur-based ligands. ${ }^{26}$ The overall toxicity and stability of the complexes are augmented by incorporating them in various nanomaterials. ${ }^{27,28}$ Among many nanomaterial hosts used to incorporate pharmaceutical agents, mesoporous silica (MCM-41) has attracted a great attention. For instance, MCM-41 with gold (III) pyridine complex showed a strong inhibitory effect on the growth of yeast and animal tumor cells. ${ }^{29}$ The biological evaluations of the grafted complexes; $\left[{ }^{64} \mathrm{Cu}\right]-\mathrm{TPPF}_{20}$ and $\left[{ }^{67} \mathrm{Ga}\right]-\mathrm{DTPA}$, on MCM41 silica host showed high radiopharmaceutical uptake in fibrosarcoma tumor in Sprague-Dawley rats. ${ }^{30,31}$ Herein, in order to prevent aggregation of the complexes and improve the stability and toxicity of 8 -HQ derivatives, ${ }^{29}$ we report a simple and efficient strategy for incorporating 8-HQ derivatives into MCM-41 by using titanium (for the first time) and aluminum alkoxides, in the light of our previous study. ${ }^{22}$

\section{Materials and Methods \\ Materials}

All chemicals were obtained from Sigma (Germany). Aluminum 2-butoxide and MCM-41 were synthesized and characterized according to our previous report. ${ }^{22}$ The synthesis of complexes and grafting process were in dry Argon, using standard Schlenk methods. ${ }^{22}$

\section{Preparation of (Q-Cl)2Ti@MCM-41}

In order to prepare $\left[\mathrm{Ti}\left(\mathrm{C}_{9} \mathrm{H}_{5} \mathrm{ClNO}\right)_{2}\left(\mathrm{C}_{3} \mathrm{H}_{7} \mathrm{O}\right)_{2}\right]$ complex (a), 5-choro-8-hydroxyquinoline $(0.72 \mathrm{~g}, 4 \mathrm{mmol})$ was added to a titanium isopropoxide $(0.358 \mathrm{~g}, 2$ mmol) solution in toluene $\left(10 \mathrm{~mL}, 0^{\circ} \mathrm{C}\right)$. The mixture immediately turned yellow and became transparent. The solution was stirred at room temperature overnight. Then, the solvents were evaporated under reduced pressure. The deep yellow crystals of the complex were obtained by hexane/ dichloromethane solution, m.p. $439 \mathrm{~K} .{ }^{1} \mathrm{H}$ NMR ( $\left.\mathrm{CDCl}_{3}, \mathrm{ppm}\right)$ : 6.98-8.58 (10H, m, $\left.\mathrm{C}_{9} \mathrm{H}_{5} \mathrm{ClNO}\right)$, 4.04-4.61 $(2 \mathrm{H}, \mathrm{m}, \mathrm{CH}), 0.97-1.23\left(12 \mathrm{H}, \mathrm{d}, \mathrm{CH}_{3}\right) .{ }^{13} \mathrm{C} \mathrm{NMR}\left(\mathrm{CDCl}_{3}\right.$, ppm): 161.81, 145.63, 141.87, 135.11, 129.48, 127.06, $122.14,116.61,111.17,78.85,77.45,77.03,76.06,25.36$, 25.16. IR ( $\left.\mathrm{cm}^{-1}, \mathrm{KBr}\right): 3050$ (C-H, aromatic), 2970 (C-H, aliphatic) $1627(\mathrm{C}=\mathrm{N}), 1573(\mathrm{C}=\mathrm{C}), 1266(\mathrm{C}-\mathrm{O}), 612(\mathrm{Ti}-$ $\mathrm{O}-\mathrm{C}$, asym), 541 (Ti-O-C, sym). UV-Vis $\left(\mathrm{CH}_{2} \mathrm{Cl}_{2}, \mathrm{~nm}\right)$ : $397\left(n \rightarrow \pi^{*}\right), 271\left(\pi \rightarrow \pi^{*}\right), 233$ (Ligand to Metal Charge Transfer) (See Supplementary data).

The resultant complex was added to a toluene solution
(10 mL) of pre-dried MCM-41 (1.0 g). The complex was allowed to react with nanoporous silica for 6 hours, and after filtration, the residue was washed with toluene and dried under reduced pressure. The formulation was accomplished by thermogravimetric and elemental analysis as $2.75(\mathrm{Q}-\mathrm{Cl})_{2} \mathrm{Ti} \cdot 100 \mathrm{SiO}_{2}$. IR $\left(\mathrm{cm}^{-1}, \mathrm{KBr}\right)$ : 3200-3700 (Si-OH), 2957 (C-H, aromatic), 2916 (C$\mathrm{H}$, aliphatic), $1606(\mathrm{C}=\mathrm{N}), 1575(\mathrm{C}=\mathrm{C}), 1236(\mathrm{C}-\mathrm{O})$, 1082 (Si-O-Si), 616 (Ti-O-C, asym), 545 (Ti-O-C, sym). Surface area $\left(\mathrm{S}_{\mathrm{BET}}\right): 810 \mathrm{~m}^{2} / \mathrm{g}$.

\section{Preparation of MCM-41 Hosts}

Using our previous procedure, ${ }^{22}$ in order to prepare $\mathrm{Q}_{2} \mathrm{Al} @ \mathrm{MCM}-41$ and (Q-Cl) ${ }_{2} \mathrm{Al} @ \mathrm{MCM}-41$ nanocomposites, 8-HQ (0.58 g, $4 \mathrm{mmol})$ and 5-choro8-hydroxyquinoline $(0.72 \mathrm{~g}, 4 \mathrm{mmol})$ were added to an aluminum 2-butoxide $(0.492 \mathrm{~g}, 2 \mathrm{mmol})$ solution, in toluene $\left(10 \mathrm{~mL}, 0^{\circ} \mathrm{C}\right)$. The mixtures immediately turned yellow and became transparent. The solutions were stirred at room temperature overnight. The resulting complexes were added to a toluene solution $(10 \mathrm{~mL})$ of pre-dried MCM-41 (1.0 g). The complexes were allowed to react with nanoporous silica for 6 hours, and after filtration, the residues were washed with toluene and dried under reduced pressure. The formulation was verified by thermogravimetric and elemental analysis as $5 \mathrm{Q}_{2} \mathrm{Al} \cdot 100 \mathrm{SiO}_{2}$ and $5(\mathrm{Q}-\mathrm{Cl})_{2} \mathrm{Al} 100 \mathrm{SiO}_{2}$.

\section{Characterization of Materials}

Infrared spectra (IR), ${ }^{1} \mathrm{H}$ and ${ }^{13} \mathrm{C}$ NMR spectra were recorded on a Shimadzu model FT-IR 4600 spectrometer and Bruker AVANCE $300-\mathrm{MHz}$ (referenced to $\mathrm{SiMe}_{4}$ ) respectively. Low angle X-ray diffraction patterns and thermal analysis (TGA-DSC) were obtained on a PhilipsPW 17C diffractometer and a Rheometric Scientific STA1500.

\section{The Anti-bacterial Assay}

Anti-bacterial activity of the nanocomposites was assessed against Escherichia coli (ATCC 1330), Salmonella typhi (PTCC 1609) and Staphylococcus aureus (PTCC 1113) using disc diffusion method. ${ }^{32}$ All mediums were autoclaved ( $15 \mathrm{lbs}$ pressure at $121^{\circ} \mathrm{C}$ ) for 15 minutes and well-mixed and poured into $100 \mathrm{~mm}$ plates $(25-30 \mathrm{~mL} /$ plate) while still molten. The wells were made with the help of a metallic borer with centers at least $20 \mathrm{~mm}$. The recommended concentrations of 12.5, 25, 50, 75 and 120 ppm of the test compounds were introduced into the respective wells. The plates were immediately incubated at $37^{\circ} \mathrm{C}$ for 24 hours. Activity against the bacterium was determined by measuring the diameter of the clearing zones (in mm) using a digital caliper and compared with standard Chloramphenicol disc (as a positive control) and substrate solution (as a negative control). The experiment was done in triplicate for each bacterium. 
The Anti-fungal Assay

The anti-fungal activity of the compounds was determined using the agar well diffusion assay on Sabouraud Dextrose Agar (SCC) (for yeasts) and Muller Hinton Agar medium (MA) (for filamentous fungi). In the case of yeast, stock cultures of two widely used unicellular eukaryotic model yeasts, Kluyveromyces marxianus (PTCC 5188) and Saccharomyces cerevisiae (ATCC 5027) were provided by Iran Researching Organization Collection (Tehran, Iran). In all steps of the experiment, we cultured SCC to produce new yeast cultures and then to perform anti-fungal assays.

For anti-fungal activity against filamentous fungi, the high cellulase producing fungi, Trichoderma reesei (PTCC 5142) was provided by Iran researching organization collection. A phytopathogenic soil-borne fungus $M$. phaseolina (Tassi) Goid, (NRCAM-27), the causal organism of charcoal rot disease, ${ }^{33}$ was the other tested soil-born fungi in this study. The MA was prepared by dissolving $33.9 \mathrm{~g}$ of MA (HiMedia) powder in $1000 \mathrm{~mL}$ of distilled water. The concentrations of test compounds as $25,50,75,120$ and $150 \mathrm{ppm}$ were introduced into the respective wells and then the plates were incubated at $28^{\circ} \mathrm{C}$. The plates were assessed after 24 to 120 hours of incubation for measuring inhibition zones. The results were compared with the diameter of inhibition zones of the chloramphenicol (as a positive control) and substrate solution (as a negative control). The mean value was calculated by performing the experiments in triplicates.

\section{Results}

Synthesis of Complexes

$\mathrm{Q}_{2} \mathrm{Al}\left(\mathrm{O}^{2} \mathrm{Bu}\right), \quad(\mathrm{Q}-\mathrm{Cl})_{2} \mathrm{Al}\left(\mathrm{O}^{2} \mathrm{Bu}\right)$ and (Q-Cl) ${ }_{2} \mathrm{Ti}\left(\mathrm{O}^{\mathrm{i}} \mathrm{Pr}\right)_{2}$ were prepared by reacting a 1:1 equivalent ratio of alkoxide and 8-HQ derivatives in toluene at room temperature according to our previous studies with slight modifications. ${ }^{19,22}$ The labile metalloorganic complex of (Q-Cl) ${ }_{2} \mathrm{Ti}\left(\mathrm{O}^{\mathrm{i}} \mathrm{Pr}\right)_{2}$ was characterized by recording their ${ }^{1} \mathrm{H}$, ${ }^{13} \mathrm{C}$ NMR spectra, UV-Vis and IR spectra for the first time which confirmed the reported crystal structure. Due to the lability of these metalloorganic complexes, they were used without isolation for grafting on MCM-41(In situ reaction).

Grafting of the Aluminum and Titanium 8-HQ Complexes to MCM-41

The prepared complexes of aluminum and titanium were incorporated directly into MCM-41 silica in toluene. The facile reaction of hydroxide groups of MCM-41 with alkoxy groups of the complexes resulted in the covalently bonding of the complex to the silica. The synthesis procedure for grafting of the complexes was illustrated in Figure 1. The fluorescent color of the solution after filtration of the final compound showed the extra complexes in the solution which confirmed the maximum loading of the complex on MCM-41. As shown in Figure 2,

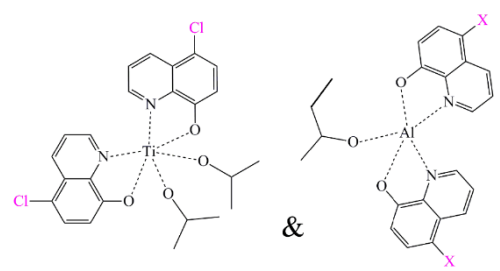

(a)

(b\&c)
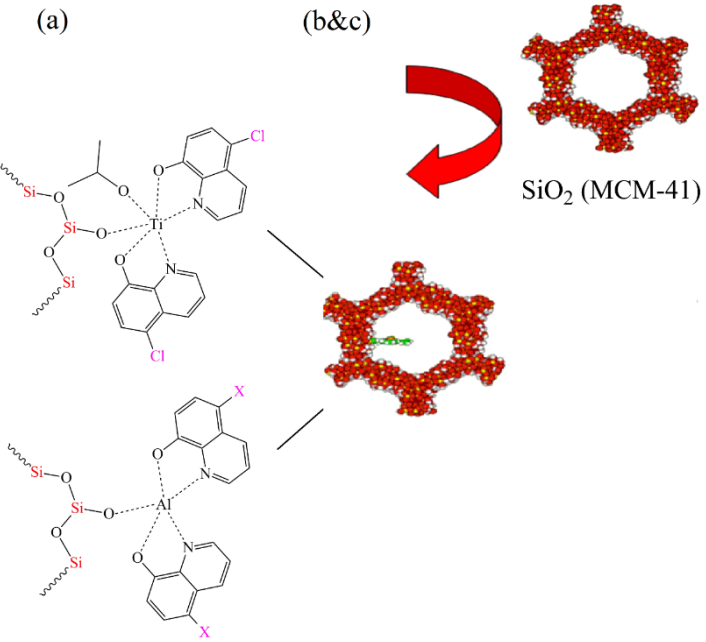

Figure 1. Grafting of the Titanium (a) and Aluminum [b. $\mathrm{R}=\mathrm{H}$ ) and $(\mathrm{c}, \mathrm{R}=\mathrm{Cl})$ ] 8- HQ Complexes on MCM-41.

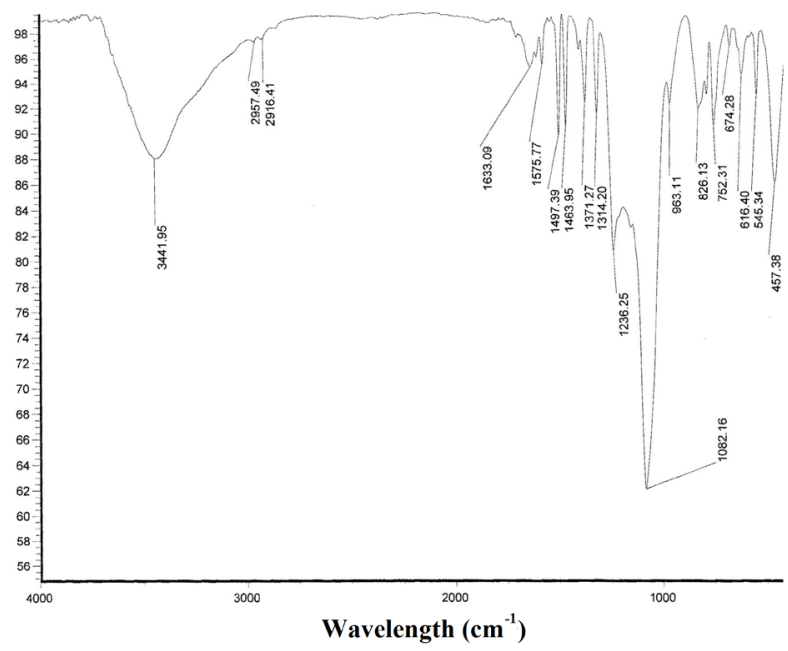

Figure 2. FT-IR Spectrum of the Grafted Titanium 8-hydroxyquinoline Complex $\left.\left((\mathrm{Q}-\mathrm{Cl})^{2} \mathrm{Ti}\left(\mathrm{O}^{\mathrm{i} P r}\right)^{2}\right)\right)$ on Mesoporous Silica.

the FT-IR spectrum of the grafted titanium 8-HQ complex on mesoporous silica showed bands in the range of 1633$1575 \mathrm{~cm}^{-1}$ and $2970 \mathrm{~cm}^{-1}$, which revealed that the 8-HQ ligand and one of the isopropoxy groups remained intact after the reaction. Formulation of grafted 5-chloro 8-HQ titanium complexes on MCM-41 was verified by TGA analysis as $2.75(\mathrm{Q}-\mathrm{Cl})_{2} \mathrm{Ti} 100 \mathrm{SiO}_{2}$ (Figure 3). Grafting of titanium on MCM-41 was demonstrated by $17.3 \%$ weight loss in the TGA curve of (Q-Cl) 2 Ti@MCM-41 at 200 to $550^{\circ} \mathrm{C}$, along with an exothermic peak in the DSC curve in the same region. This indicated lower stability of the 


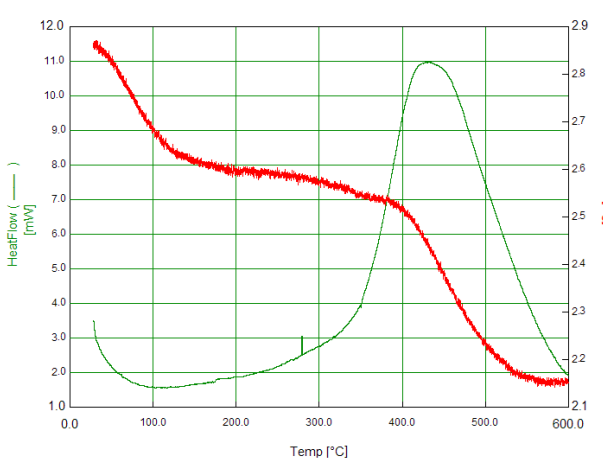

Figure 3. TGA and DSC Curves of $(\mathrm{Q}-\mathrm{Cl}){ }_{2} \mathrm{Ti} @ \mathrm{MCM}-41$

titanium than the aluminum complexes. ${ }^{22}$ This fact lies in the presence of the isopropoxy group on the mesoporous silica which showed that the lability of the titanium (IV) 8-hydroxyquinoline complex was less than the aluminum (III) 8-hydroxyquinoline complexes. The (100) reflection within the $2 \theta$ range of $2-3^{\circ}$ in low angle X-ray diffraction patterns of analyses, clearly indicated that the twodimensional hexagonal mesoporous structure $(P 6 \mathrm{~mm})$ of MCM-41 was maintained after introducing titanium complex (Figure 4$){ }^{22}$

The Anti-bacterial Activity of the Nanocomposites It was observed that (Q-Cl) ${ }_{2}$ Ti@MCM-41 nanocomposite had anti-bacterial activity against $S$. aureus at concentrations of 50, 75 and $120 \mathrm{ppm}$ and its activity was dose-dependent. However, the anti-bacterial effect of this nanomaterial on E. coli and S. typhi was started at the concentration of 75 ppm. Q 2 Al@MCM-41 weakly inhibited the bacterial growth of E. coli at 75 and 120 ppm concentrations (Table 1). (Q-Cl) $2 \mathrm{Al} @ \mathrm{MCM}-41$ did not show any anti-bacterial activity at any concentration (Figure 5).

The Anti-fungal Activity of the Nanocomposites As shown in Table 2, all materials had anti-yeast activity and (Q-Cl) ${ }_{2}$ Ti@MCM-41 was the strongest, showing yeast inhibition activity at 50 ppm concentration. $\mathrm{Q}_{2} \mathrm{Al} @$ MCM-41 showed the minimum anti-fungal activity. The (Q-Cl) Ti@MCM-41 had considerable anti-yeast

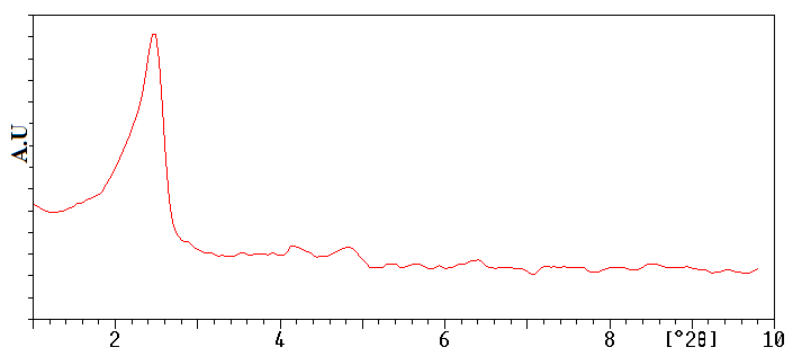

Figure 4. XRD Patterns of (Q-Cl) 2 Ti@MCM-41.

activity in comparison with other tested compounds. $K$. marxianus presented more resistance than the $S$. cerevisiae in exposure to all the compounds. $(\mathrm{Q}-\mathrm{Cl})_{2} \mathrm{Al} @$ MCM-41 showed anti-fungal potential (in both yeast and filamentous fungi), however, no anti-bacterial potency was observed. $M$. phaseolina completely resisted against $\mathrm{Q}_{2} \mathrm{Al} @ \mathrm{MCM}-41$ and had less sensitivity than $T$. reesei to $(\mathrm{Q}-\mathrm{Cl})_{2} \mathrm{Al} @ \mathrm{MCM}-41$ and $(\mathrm{Q}-\mathrm{Cl})_{2} \mathrm{Ti} @ \mathrm{MCM}-41$ (Figure 6).

\section{Discussion}

Complexes of 8-hydroxyquinoline derivatives of titanium and aluminum were adjoined with MCM-41 nano silica using condensation of hydroxide groups of the MCM41 beds modified by alkoxy groups. The concentrations of complexes were adjusted to maximum to achieve the highest possible availability and stability of antimicrobial material on MCM-41 beds. Therefore, after grafting of complexes on MCM-41 nano silica, the color of solutions was still visible. Notably, no leaching was noted in the grafted nano silica complexes in exposure to polar or non-polar solvents. The anti-microbial (bacterium and fungi) effects of the tested nanoparticles used in this study were found to be very potent. These activities have also been confirmed in previous studies. ${ }^{34-36}$ The antimicrobial effects of the agents were dose-dependent and more pronounced against gram-positive bacteria than gramnegative organisms, ${ }^{37}$ however, Shrivastava et al reported that gram-positive bacteria had higher resistance against silver nanoparticles. ${ }^{38}$

In the case of anti-fungal activity, all the tested isolates

Table 1. The Results of Antibacterial Activity of Compounds by Disc Diffusion Method

\begin{tabular}{|c|c|c|c|c|c|c|c|c|c|c|c|c|}
\hline \multirow[t]{2}{*}{ Bacterium } & \multicolumn{4}{|c|}{$\mathrm{Q}_{2} \mathrm{Al} @ \mathrm{MCM}-41$ (Concentration ppm) } & \multicolumn{4}{|c|}{$\begin{array}{l}(\mathrm{Q}-\mathrm{Cl})_{2} \mathrm{Al} @ \mathrm{MCM}-41 \\
\text { (concentration ppm) }\end{array}$} & \multicolumn{4}{|c|}{$(\mathrm{Q}-\mathrm{Cl})_{2} \mathrm{Ti} @ \mathrm{MCM}-41$ (concentration ppm) } \\
\hline & $<50$ & 50 & 75 & 120 & $<50$ & 50 & 75 & 120 & $<50$ & 50 & 75 & 120 \\
\hline $\begin{array}{l}\text { E. coli (inhibition } \\
\text { zone, } \mathrm{mm} \text { ) }\end{array}$ & $\mathrm{n}^{*}$ & $n$ & $0.03 \pm 0.66^{e}$ & $1.77 \pm 0.52^{\mathrm{d}}$ & $\mathrm{n}$ & $\mathrm{n}$ & $\mathrm{n}$ & $\mathrm{n}$ & $\mathrm{n}$ & $\mathrm{n}$ & $1.1 \pm 0.34^{\mathrm{d}}$ & $5.43 \pm 0.74^{b}$ \\
\hline $\begin{array}{l}\text { S. typhi (inhibition } \\
\text { zone, } \mathrm{mm} \text { ) }\end{array}$ & $n$ & $n$ & $\mathrm{n}$ & $0.05 \pm 0.42^{\mathrm{e}}$ & $\mathrm{n}$ & $\mathrm{n}$ & $\mathrm{n}$ & $\mathrm{n}$ & $\mathrm{n}$ & $\mathrm{n}$ & $0.3 \pm 0.4^{\mathrm{e}}$ & $1.07 \pm 0.84^{\mathrm{d}}$ \\
\hline $\begin{array}{l}\text { S. aureus (inhibition } \\
\text { zone, } \mathrm{mm} \text { ) }\end{array}$ & $\mathrm{n}$ & $n$ & $\mathrm{n}$ & $\mathrm{n}$ & $n$ & $n$ & $n$ & $\mathrm{n}$ & $n$ & $1.04 \pm 0.08^{\mathrm{d}}$ & $3.9 \pm 0.86^{c}$ & $7.67 \pm 0.37^{\mathrm{a}}$ \\
\hline
\end{tabular}

${ }^{*}$ n: negative, a-e: Different superscript small letters within a row denote significant differences $(P<0.01$, Duncan's multiple range test) in each nanocompound concentration. 
Table 2. The Results of Fungicidal Activity of Compounds by Agar Well Diffusion Assay Method

\begin{tabular}{|c|c|c|c|c|c|c|c|c|c|c|c|c|}
\hline \multirow{2}{*}{ Fungi } & \multicolumn{4}{|c|}{$\begin{array}{c}\mathrm{Q}_{2} \mathrm{Al} @ \mathrm{MCM}-41 \\
\text { (Concentration ppm) }\end{array}$} & \multicolumn{4}{|c|}{$\begin{array}{c}(\mathrm{Q}-\mathrm{Cl})_{2} \mathrm{Al} @ \mathrm{MCM}-41 \text { (Concentration } \\
\mathrm{ppm})\end{array}$} & \multicolumn{4}{|c|}{$(\mathrm{Q}-\mathrm{Cl})_{2} \mathrm{Ti} @ \mathrm{MCM}-41$ (Concentration ppm) } \\
\hline & 50 & 75 & 120 & 150 & 50 & 75 & 120 & 150 & 50 & 75 & 120 & 150 \\
\hline $\begin{array}{l}\text { S. cerevisiae(inhibition } \\
\text { zone, } \mathrm{mm} \text { ) }\end{array}$ & $n^{*}$ & $\mathrm{n}$ & $\begin{array}{l}1.03 \pm \\
0.21 \mathrm{~g}\end{array}$ & $\begin{array}{l}1.77 \pm \\
0.52^{f}\end{array}$ & $\mathrm{n}$ & $\begin{array}{l}4.5^{ \pm} \\
0.12^{\mathrm{d}}\end{array}$ & $\begin{array}{c}10.23 \pm \\
0.16^{c}\end{array}$ & $\begin{array}{l}11.9 \pm \\
0.25^{b}\end{array}$ & $\begin{array}{r}2.01 \pm \\
0.44^{f}\end{array}$ & $\begin{array}{l}5.3 \pm \\
0.82^{\mathrm{d}}\end{array}$ & $\begin{array}{c}11.46 \pm \\
0.21^{\mathrm{b}}\end{array}$ & $\begin{array}{l}12.8 \pm \\
0.25^{a}\end{array}$ \\
\hline $\begin{array}{l}\text { K. marxianus } \\
\text { (inhibition zone, mm) }\end{array}$ & $\mathrm{n}$ & $\mathrm{n}$ & $\mathrm{n}$ & $\begin{array}{r}0.97 \pm \\
0.15^{g}\end{array}$ & $\mathrm{n}$ & $n$ & $\begin{array}{l}1.01 \pm \\
0.54^{8}\end{array}$ & $\begin{array}{l}1.37 \pm \\
0.44^{f}\end{array}$ & $n$ & $\begin{array}{l}1.06 \pm \\
0.54^{9}\end{array}$ & $\begin{array}{l}2.6 \pm \\
0.75^{\mathrm{e}}\end{array}$ & $\begin{array}{l}2.9 \pm \\
0.78^{\mathrm{e}}\end{array}$ \\
\hline $\begin{array}{l}\text { M. phaseolina } \\
\text { (inhibition zone, mm) }\end{array}$ & $\mathrm{n}$ & $\mathrm{n}$ & $\mathrm{n}$ & $n$ & $\mathrm{n}$ & $\mathrm{n}$ & $n$ & $\begin{array}{l}0.5 \pm \\
0.48^{\mathrm{h}}\end{array}$ & $\mathrm{n}$ & $\mathrm{n}$ & $n$ & $\begin{array}{l}0.4 \pm \\
0.33^{\mathrm{h}}\end{array}$ \\
\hline $\begin{array}{l}\text { T. reesei (inhibition } \\
\text { zone, } \mathrm{mm} \text { ) }\end{array}$ & $\mathrm{n}$ & $\mathrm{n}$ & $\mathrm{n}$ & $\begin{array}{l}1.08 \pm \\
0.27^{8} \\
\end{array}$ & $\mathrm{n}$ & $n$ & $\begin{array}{c}0.87 \pm \\
0.41^{\mathrm{h}}\end{array}$ & $\begin{array}{l}3.77 \pm \\
0.78^{\mathrm{e}} \\
\end{array}$ & $\mathrm{n}$ & $\mathrm{n}$ & $\begin{array}{l}1.5 \pm \\
0.98^{8}\end{array}$ & $\begin{array}{l}1.9 \pm \\
0.24^{f}\end{array}$ \\
\hline
\end{tabular}

*n: negative, a-e: Different superscript small letters within a row denote significant differences $(P<0.01$, Duncan's multiple range test) in each nanocompound concentration.
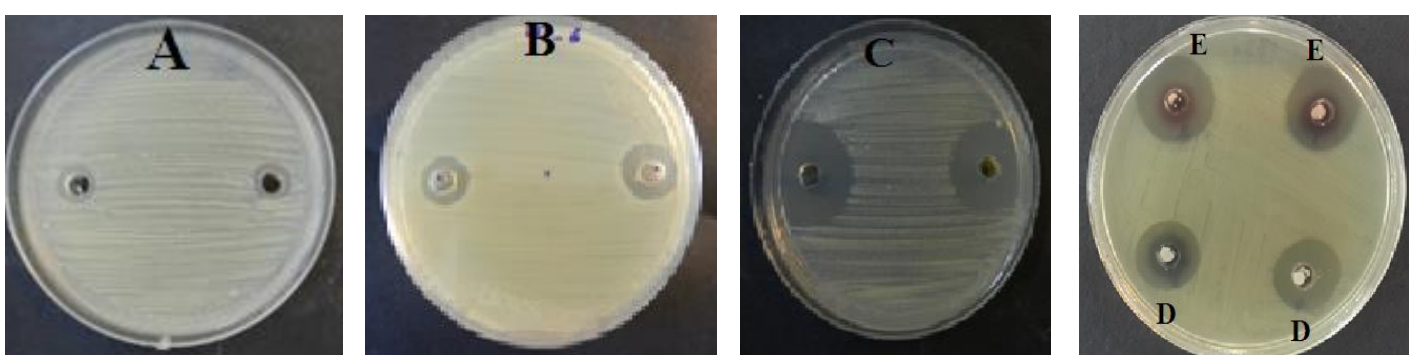

Figure 5. The antibacterial activity index was the average diameter of the clearing zones (mm) presented in $50 \mathrm{ppm}(\mathrm{A}), 75 \mathrm{ppm}(\mathrm{B})$ and $120 \mathrm{ppm}(\mathrm{C})$ concentrations of (Q-Cl) $)_{2} @ M C M-41$ against E. coli, and 75 ppm (D) and 120 ppm (E) concentrations of (Q-Cl) $)_{2} @ M C M-41$ against $S$. aureus subsp. areas using the digital caliper in three replicates.

belonged to the Ascomycota family. The yeasts ( $S$. cerevisiae and K. marxianus) showed more sensitivity to these compounds than the filamentous fungi ( $T$. reesei and M. phaseolina) and this may present the role of mycelial body in resistance against antibiotic stresses. The less sensitivity of $M$. phaseolina than the T. reesei was observed in all treatments that may be related to the ability of $M$. phaseolina to produce more pigments. The role of pigmentation in chemical resistance in fungi has been shown in many studies. ${ }^{34-36}$ In addition, the resistance of $K$. marxianus and $M$. phaseolina against nanomaterial make them suitable candidates for bio-
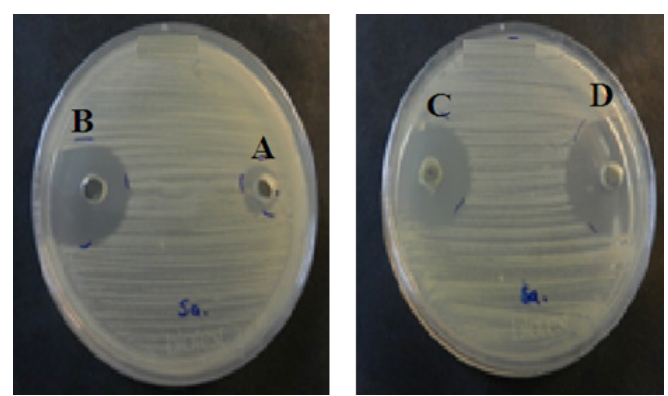

Figure 6. The antifungal activity index was the average diameter of the clearing zones $(\mathrm{mm})$ presented in $500 \mathrm{ppm}(\mathrm{A}), 750 \mathrm{ppm}$ (B) $1200 \mathrm{ppm}$ (C) and 1500 ppm (D) concentrations of (Q-Cl) $)_{2} \mathrm{Al} @ \mathrm{MCM}-41$ against $S$. cerevisiae. synthesis of nanoparticles. Bare complexes of aluminum and titanium are not stable in aqueous medium, therefore, their MICs (minimum inhibitory concentration) could not be determined accurately. It was already shown that similar complexes of titanium alkoxides with moisturestable ligands also had no antifungal activity. ${ }^{26}$ Our study showed that the substitution of the metallic core from aluminum (III) to titanium (IV) improved the cytotoxicity of compounds.

\section{Conclusion}

This study showed that it is possible to prepare moisturestable titanium (IV) and aluminum (III) 8-HQ derivatives complexes with direct grafting on MCM-41 mesoporous nanotube. The complexes were biocompatible and showed anti-microbial (bacterium and fungi) activities. The prepared materials were stable both under air and high temperature (at least up to $200^{\circ} \mathrm{C}$ ). These nanocomposites were well dispersed in water supporting their potential chemotherapeutic application in clinical practice.

\section{Conflict of interests}

There is no conflict of interests in this study.

\section{Ethical Issues}

There is no experiment that needed approval. 


\section{References}

1. Tshuva EY, Peri D. Modern cytotoxic titanium(IV) complexes; Insights on the enigmatic involvement of hydrolysis. Coord Chem Rev. 2009;253(15-16):2098-2115. doi:10.1016/j.ccr.2008.11.015

2. Tzubery A, Tshuva EY. Trans titanium(IV) complexes of salen ligands exhibit high antitumor activity. Inorg Chem. 2011;50(17):7946-7948. doi:10.1021/ic201296h

3. Sinha S, Srivastava AK, Tripathi CM, Pandey OP, Sengupta SK. Synthesis, spectroscopic, and antimicrobial studies of binuclear metallocene ( $\mathrm{M}=\mathrm{Ti}$, $\mathrm{Zr}$, or Hf) derivatives of bis(mercaptoazoles). Bioinorg Chem Appl. 2007:87918. doi:10.1155/2007/87918

4. Samuel B, Tummalapalli K, Giri PV, Pathak M. Novel heteroleptic complexes of titanium(IV) derived from 2-hydroxyacetophenone: synthesis, characterization, antibacterial and molecular docking studies. Med Chem Res. 2014;23(2):699-707. doi:10.1007/s00044013-0660-y

5. Zeng WF, Chen YS, Chiang MY, Chern SS, Cheng CP. Preparation and structures of complexes of titanium(IV) and 8-hydroxyquinoline: TiQ2(Opri)2 and [TiQ2( $\mu-\mathrm{O})] 4 \cdot 6 \mathrm{H} 2 \mathrm{O}$. Polyhedron. 2002;21(11):1081-1087. doi:10.1016/S02775387(02)00873-2

6. Vashi RT, Patel SB, Patel H. DNA binding and anti-microbial studies of ag(ii) and cu(ii) metal complexes containing mixed ligands of 1,10-phenanthroline and 8-hydroxyquinoline. Int J Pharma Bio Sci. 2013;4(1):172-178.

7. Malghe YS, Prabhu RC, Raut RW. Synthesis, characterization and biological activities of mixed ligand $\mathrm{Zr}(\mathrm{IV})$ complexes. Acta Pol Pharm. 2009;66(1):45-50.

8. Reis DC, Pinto MC, Souza-Fagundes EM, et al. Investigation on the pharmacological profile of antimony(III) complexes with hydroxyquinoline derivatives: anti-trypanosomal activity and cytotoxicity against human leukemia cell lines. Biometals. 2011;24(4):595-601. doi:10.1007/s10534-011-9407-8

9. Tardito S, Barilli A, Bassanetti I, et al. Copper-dependent cytotoxicity of 8-hydroxyquinoline derivatives correlates with their hydrophobicity and does not require caspase activation. J Med Chem. 2012;55(23):10448-10459. doi:10.1021/jm301053a

10. Heidary DK, Howerton BS, Glazer EC. Coordination of hydroxyquinolines to a ruthenium bis-dimethyl-phenanthroline scaffold radically improves potency for potential as antineoplastic agents. J Med Chem. 2014;57(21):8936-8946. doi:10.1021/ jm501043s

11. Oliveri V, Vecchio G. 8-Hydroxyquinolines in medicinal chemistry: A structural perspective. Eur J Med Chem. 2016;120:252-274. doi:10.1016/j.ejmech.2016.05.007

12. Zhang HR, Meng T, Liu YC, et al. Synthesis, Structure Characterization and Antitumor Activity Study of a New Iron(III) Complex of 5-Nitro-8-hydroxylquinoline (HNOQ). Chem Pharm Bull (Tokyo). 2016;64(8):1208-1217. doi:10.1248/bpb.c16-00330

13. Fazaeli Y, Najafi E, Amini MM, Ng SW. Bis(mu-2-methylquinolin-1-ium-8-olato-kappaO:O')bis-[(2-methyl-quinolin-1ium-8- olato-kappaO)tris-(nitrato-kappaO,O')lanthanum(III)]. Acta Crystallogr Sect E Struct Rep Online. 2009;65(Pt 7):m711. doi:10.1107/s1600536809019746

14. Fazaeli Y, Amini MM, Ng SW. Bis(mu-2-methyl-8-oxidoquinolin1-ium-kappaO:O)bis-[(acetato-kappaO,O') (2-methyl8-oxidoquinolin-1-ium-kappaO)bis-(nitrato-kappaO,O') lanthanum(III)]. Acta Crystallogr Sect E Struct Rep Online. 2010;66(Pt 2):m163. doi:10.1107/s1600536809055743

15. Fazaeli Y, Najafi E, Amini MM, Ng SW. Dichloridobis(5,7-
dichloro-quinolin-8-olato-kappaN,O)tin(IV). Acta Crystallogr Sect E Struct Rep Online. 2009;65(Pt 3):m270. doi:10.1107/ s1600536809004371

16. Amini MM, Fazaeli Y, Mohammadnezhad G, Khavasi HR. Structural and spectroscopic characterizations of tetra-nuclear niobium $(V)$ complexes of quinolinol derivatives. Spectrochim Acta A Mol Biomol Spectrosc. 2015;144:192-199. doi:10.1016/j. saa.2015.02.077

17. Fazaeli Y, Amini MM, Ng SW. Bis(isopropoxido-kappaO)bis(2-methyl-quinolin-8-olato-kappaN,O)titanium(IV). Acta Crystallogr Sect E Struct Rep Online. 2008;64(Pt 12):m1509. doi:10.1107/s1600536808035460

18. Fazaeli Y, Najafi E, Amini MM, Khavasi HR. Di-mu-ethano-latobis-[diethano-lato(2-methyl-quinolin-8-olato)titanium(IV)]. Acta Crystallogr Sect E Struct Rep Online. 2009;65(Pt 12):m1531. doi:10.1107/s1600536809045796

19. Fazaeli Y, Najafi E, Amini MM, Ng SW. Bis(5-chloro-quinolin8-olato-kappaN,O)bis-(propan-2-olato-kappaO)titanium(IV). Acta Crystallogr Sect E Struct Rep Online. 2009;65(Pt 3):m271. doi:10.1107/s1600536809004383

20. Fazaeli Y, Jalilian AR, Amini MM, et al. Radiosynthesis and biological evaluation of 111In-tris [8-Hydroxy-2methylquinoline] complex as a possible imaging agent. Iran J Nucl Med. 2011;19(2):20-27.

21. Fazaeli Y, Amini MM, Najafi E, et al. Synthesis and characterization of 8-hydroxyquinoline complexes of tin(IV) and their application in organic light emitting diode. J Fluoresc. 2012;22(5):1263-1270. doi:10.1007/s10895-012-1068-7

22. Fazaeli Y, Amini MM, Mohajerani E, Sharbatdaran M, Torabi N. Grafting aluminum(III) 8-hydroxyquinoline derivatives on MCM-41 mesoporous silica for tuning of the light emitting color. J Colloid Interface Sci. 2010;346(2):384-390. doi:10.1016/j. jcis.2010.03.032

23. Di Vaira M, Bazzicalupi C, Orioli P, Messori L, Bruni B, Zatta P. Clioquinol, a drug for Alzheimer's disease specifically interfering with brain metal metabolism: structural characterization of its zinc(II) and copper(II) complexes. Inorg Chem. 2004;43(13):37953797. doi:10.1021/ic0494051

24. Mansouri-Torshizi H, Saeidifar M, Rezaei-Behbehani GR, Divsalar A, Saboury AA. DNA binding studies and cytotoxicity of ethylenediamine 8-hydroxyquinolinato palladium(II) chloride. J Chin Chem Soc. 2010;57(6):1299-1308. doi:10.1002/ jccs.201000192

25. Siddiqi ZA, Shahid M, Khalid M, Kumar S. Antimicrobial and SOD activities of novel transition metal ternary complexes of iminodiacetic acid containing alpha-diimine as auxiliary ligand. Eur J Med Chem. 2009;44(6):2517-2522. doi:10.1016/j. ejmech.2009.01.025

26. Samuel B, Ethiraj KR, Pathak M. Moisture stable heteroleptic titanium (IV) complexes derived from 8-hydroxyquinoline: synthesis, antibacterial, and antifungal studies. Med Chem Res. 2015;24(4):1504-1513. doi:10.1007/s00044-014-1234-3

27. Fazaeli Y, Akhavan O, Rahighi R, Aboudzadeh MR, Karimi E, Afarideh H. In vivo SPECT imaging of tumors by 198,199Aulabeled graphene oxide nanostructures. Mater Sci Eng C Mater Biol Appl. 2014;45:196-204. doi:10.1016/j.msec.2014.09.019

28. Fazaeli Y, Rahighi R, Tayyebi A, Feizi S. Synthesis, characterization and biological evaluation of a well dispersed suspension of gallium-68-labeled magnetic nanosheets of graphene oxide for in vivo coincidence imaging. Radiochim Acta. 2017;105(1):65-73. doi:10.1515/ract-2015-2556 
29. Fazaeli Y, Amini MM, Ashourion H, et al. Grafting of a novel gold(III) complex on nanoporous MCM-41 and evaluation of its toxicity in Saccharomyces cerevisiae. Int J Nanomedicine. 2011;6:3251-3257. doi:10.2147/ijn.s25449

30. Fazaeli Y, Feizi S, Jalilian AR, Hejrani A. Grafting of $[(64) \mathrm{Cu}]-$ TPPF20 porphyrin complex on functionalized nano-porous MCM-41 silica as a potential cancer imaging agent. Appl Radiat Isot. 2016;112:13-19. doi:10.1016/j.apradiso.2016.03.003

31. Fazaeli Y, Asgari Z. DTPA-functionalized nano-porous MCM41 silica: a new potential nanoengineered labeled composite for diagnostic applications. Iranian Journal of Science and Technology, Transactions A: Science. 2018;42(2):497-504. doi:10.1007/s40995-016-0047-2.

32. Vincent JG, Vincent HW, Morton J. Filter Paper disc modification of the Oxford cup penicillin determination. Proc Soc Exp Biol Med. 1944;55(3):162-164. doi:10.3181/00379727-55-14502

33. Islam MS, Haque MS, Islam MM, et al. Tools to kill: genome of one of the most destructive plant pathogenic fungi Macrophomina phaseolina. BMC Genomics. 2012;13:493. doi:10.1186/14712164-13-493

34. Sondi I, Salopek-Sondi B. Silver nanoparticles as antimicrobial agent: a case study on E. coli as a model for gram-negative bacteria. J Colloid Interface Sci. 2004;275(1):177-182. doi:10.1016/j. jcis.2004.02.012

35. Ayala-Nunez NV, Lara Villegas HH, del Carmen Ixtepan Turrent L, Rodriguez Padilla C. Silver nanoparticles toxicity and bactericidal effect against methicillin-resistant Staphylococcus aureus: nanoscale does matter. NanoBiotechnology. 2009;5(14):2-9. doi:10.1007/s12030-009-9029-1

36. Birla SS, Tiwari VV, Gade AK, Ingle AP, Yadav AP, Rai MK. Fabrication of silver nanoparticles by Phoma glomerata and its combined effect against Escherichia coli, Pseudomonas aeruginosa and Staphylococcus aureus. Lett Appl Microbiol. 2009;48(2):173-179. doi:10.1111/j.1472-765X.2008.02510.x

37. Rai MK, Deshmukh SD, Ingle AP, Gade AK. Silver nanoparticles: the powerful nanoweapon against multidrug-resistant bacteria. J Appl Microbiol. 2012;112(5):841-852. doi:10.1111/j.13652672.2012.05253.x

38. Shrivastava S, Bera T, Roy A, Singh G, Ramachandrarao P, Dash D. Characterization of enhanced antibacterial effects of novel silver nanoparticles. Nanotechnology. 2007;18(22):225103. doi:10.1088/0957-4484/18/22/225103 